\title{
Research on the revitalization of the cultural tourism industry in the post-epidemic era-a case study of Guangxi
}

\author{
Jixuan Che ${ }^{1}$, Peng Yang ${ }^{2,}$, Jiayue $\mathrm{Wu}^{1}$, and Yafei $\mathrm{Gao}^{1}$ \\ ${ }^{1}$ College of Economics and Management, Nanning Normal University, 530000, Nanning, Guangxi, PRC \\ ${ }^{2}$ Department of Economic Development and Strategic Decision Making, Guangxi Academy of Social Science, 530000, Nanning, \\ Guangxi, PRC
}

\begin{abstract}
As a sudden public health event, the COVID-19 epidemic has brought a tremendous impact on the economic and social development of China. Its biggest and most direct impact is in the tertiary industry, especially the cultural tourism industry, which has a more far-reaching impact. This paper takes Guangxi as an example to study the current situation, problems, and future development direction of the cultural tourism industry in the post-epidemic era. The study found that the response to the epidemic in ethnic minority areas represented by Guangxi was timely and rapid, but due to their industrial resilience and the impact of the epidemic, the revitalization of the culture and tourism industry is still facing severe challenges. Therefore, this article put forward the key countermeasure to promote the cultural tourism industry revitalization of ethnic minority areas from list management, elements of development management, project construction, industry integration, and international cooperation, to provide policy recommendations and theoretical basis for the revitalization of the cultural tourism industry in ethnic minority areas.
\end{abstract}

\section{Introduction}

China's ethnic minority areas (such as Inner Mongolia, Xinjiang, Guizhou, Guangxi, Yunnan, Tibet, Ningxia, Gansu) are mostly located in the western region. Although the economic level is relatively backward, they have significant advantages in ecological resources, which provide unique conditions for the development of the cultural tourism industry. With the deepening of China's attention to the cultural tourism industry and the gradual expansion of China's cultural tourism market scale, it will be a new era in the 14th Five-Year Plan period, and even in the future, the cultural tourism industry will become one of the most important ways to promote the economic development of ethnic minority areas and the strategy of western development.

However, in the post-epidemic era, the normalization of epidemic prevention and control and the repeated "intrusion" of the epidemic have brought severe challenges to the development of the cultural tourism industry in ethnic minority areas. As a trend industry in the future, the cultural tourism industry has important strategic significance and key role in promoting consumption transformation and building a "dual circulation" development pattern, and has great significance for the future industrial development and economic transformation and upgrading. Therefore, it is necessary to thoroughly study the environment and challenges faced by the cultural tourism industry of the ethnic minority areas in the post-epidemic era, find a suitable way for the revival and development of cultural tourism industry in ethnic minority areas, optimize and improve the business environment, accelerate the upgrading of the cultural tourism industry, accelerate the cultivation of new momentum of economic development, and promote the high-quality development of cultural tourism industry in ethnic minority areas in the post epidemic era.

\section{Literature Review}

As an important future trend industry, the cultural tourism industry has been discussed and studied from the aspects of industrial development and layout, transformation, upgrading, optimization, and innovation by academia, some valuable research results have been formed. The main point of view focuses on culture and tourism integration, and advocates to promote the integrated development from the development of cultural tourism industry at the county level, the cultivation of cultural and tourism professionals, and the joint efforts of the government and market. ${ }^{[1]}$ And from the perspective of industrial integration development, it constructs the comprehensive evaluation index system of cultural tourism industry development, calculates the comprehensive development level of the cultural tourism industry in China's provinces, ${ }^{[2]}$ and considers that the most powerful power source for the coordinated development of cultural tourism industry is consumer demand, and the development level has a significant relationship with the government policy conditions, the 
policy intensity has a "near strong and far weak" positive influence on the scale expansion and investment level of the cultural tourism industry. ${ }^{[3]}$

At present, most of the research objects are in the eastern and central regions, ${ }^{[4]}$ but the development of the cultural tourism industry in ethnic minority areas is less involved. However, famous cities, towns, villages with ethnic characteristics in ethnic minority areas are the main battlefields of cultural tourism industry integration development. ${ }^{[5]}$ The development of the cultural tourism industry in ethnic minority areas should focus on the systematic and overall development, and deal with the three main relationships. In terms of the development of the cultural tourism industry, academia has formed different development research tracks in urban and rural areas. The cultural tourism industry is an important part of the county economy and effective help to The Rural Vitalization Strategy. ${ }^{[6-7]}$ It has the advantage of the cultural resources and can effectively help the development of the cultural tourism industry, and the latecomer ranks first. After the outbreak of COVID-19, as a highly sensitive industry, the market demand and supply of the cultural tourism industry had a "double-ended downturn" phenomenon. The tourism industry once suffered heavy losses. ${ }^{[8]}$ After entering the normalization of prevention and control, the cultural tourism industry appeared new opportunities and directions, the consumption demand became more pragmatic and healthier, [9] and the consumption supply became diversified and orderly, which is conducive to the new format, new mode, and new development of the industry. New products and services emerge endlessly, laying a good foundation for the follow-up development of the industry.

In general, the current studies are worth noting in two aspects: one is the relative lack of research on the development of cultural tourism industry in western regions, especially in ethnic minority areas; the other is the relative lack of research on the revitalization of the cultural tourism industry in ethnic minority areas after the epidemic. Therefore, this study takes Guangxi as a sample to research the revitalization of the cultural tourism industry in the post-epidemic era, trying to find scientific and reasonable countermeasures to revitalize the cultural tourism industry, and then provide countermeasures and suggestions for the revitalization of the cultural tourism industry in ethnic minority areas.

\section{The influence of COVID-19 on the development of Guangxi cultural tourism industry}

\subsection{COVID-19 has led to heavy losses in the cultural tourism industry}

COVID-19 has brought a strong impact on Guangxi's cultural tourism industry. The consumption of the cultural

Department of Culture and Tourism of Guangxi Zhuang Autonomous Region, Data report on main tourism indicators in tourism market has been suppressed. Due to the need to further prevent and control the epidemic, the scenic spots, restaurants, accommodation, and tourist traffic have been completely suspended. Many enterprises are empty, profits have dropped sharply and the total number of tourists has been reduced. The overall driving capacity of the cultural tourism industry is weakened. Cultural tourism enterprises, such as travel agencies, OTA, and other channel end enterprises, have been seriously damaged, various scenic spots, restaurants, hotels, and other resource end enterprises are under increasing pressure, conference and exhibition, cultural and creative design, and other service end enterprises are in trouble, and human cost, rigid expenditure, the sharp decrease in income, brain drain and other problems aggravate the plight of enterprises. ${ }^{[10]}$ The short-term investment of cultural and tourism projects slows down or suspends, the construction and proposed projects are delayed, or the shutdown or reassessment is caused by other reasons.

\subsection{Polarization of culture tourism consumption market}

With the domestic epidemic situation basically under control and the foreign epidemic situation still grim, the culture tourism consumer market presents a state of polarization. First, the domestic market is gradually warming up, and second, the foreign market is obviously declining. According to the data released by the Department of Culture and Tourism of Guangxi Zhuang Autonomous Region, in the first three quarters of 2020, the total domestic tourism consumption in Guangxi was 459.38 billion RMB, returning to $58.0 \%$ of the same period, and the international tourism (foreign exchange) consumption was 117 million USD, a year-on-year decrease of $95.7 \%$. ${ }^{\odot}$ In the first half of this year, the market consumption was depressed due to the influence of the COVID-19. After entering the normal prevention and control period, the domestic market gradually recovered with the implementation of a series of supporting policies for resuming production and resuming work in the first half of the year. Due to the severe epidemic situation in foreign countries and the requirements of domestic epidemic prevention and control work, the foreign consumer market continues to decline, but overall, the domestic consumer part of Guangxi cultural tourism market occupies the main position, and the cultural tourism consumer market is in a state of recovery overall.

$\begin{array}{lll}\text { the first three quarters of } & 2020 \text {, } \\ \text { http://wlt.gxzf.gov.cn/zwgk/sjfb/t6721369.shtml. } & \end{array}$ 
Table1. Guangxi tourism data before and after COVID-19

\begin{tabular}{|c|c|c|c|c|}
\hline Project & $\begin{array}{l}\text { First- } \\
\text { quarter } \\
2019\end{array}$ & $\begin{array}{c}\text { January- } \\
\text { June } \\
2019\end{array}$ & $\begin{array}{c}\text { First- } \\
\text { quarter } \\
\mathbf{2 0 2 0}\end{array}$ & $\begin{array}{c}\text { Janu } \\
\text { ary- } \\
\text { June } \\
2020\end{array}$ \\
\hline $\begin{array}{c}\text { Accumulated } \\
\text { reception of } \\
\text { domestic and } \\
\text { foreign } \\
\text { tourists } \\
(100 \text { million } \\
\text { trips })\end{array}$ & 1.92 & 4.24 & 0.524 & 1.79 \\
\hline $\begin{array}{c}\text { Domestic } \\
\text { tourists (100 } \\
\text { million trips) }\end{array}$ & 1.91 & 4.21 & 0.522 & 1.79 \\
\hline $\begin{array}{l}\text { Inbound } \\
\text { overnight } \\
\text { visitors }(10 \\
\text { thousand } \\
\text { trips })\end{array}$ & 112.49 & 294.27 & 20.62 & 20.99 \\
\hline $\begin{array}{l}\text { Total tourism } \\
\text { consumption } \\
(100 \text { million } \\
\text { RMB })\end{array}$ & 2261.27 & 4957.81 & 633.90 & 1971.45 \\
\hline $\begin{array}{c}\text { Total domestic } \\
\text { tourism } \\
\text { consumption } \\
(100 \text { million } \\
\text { RMB })\end{array}$ & 2224.61 & 4859.59 & 626.54 & 1963.95 \\
\hline $\begin{array}{l}\text { International } \\
\text { tourism } \\
\text { consumption } \\
(100 \text { million } \\
\text { USD })\end{array}$ & 5.54 & 14.84 & 1.07 & 1.09 \\
\hline
\end{tabular}

Data source: Department of Culture and Tourism of Guangxi Zhuang Autonomous Region.

\section{Analysis on the dilemma of Guangxi Cultural tourism industry development in the post-epidemic Era}

\subsection{The scale of the industry is small and lacks the competitive advantage over the surrounding areas}

The ethnic minority are rich areas of cultural and tourism resources in China. However, due to the lagging behind in the development of the tourism industry and the lack of competitive mode, these areas are lacking competitive advantages. After the outbreak of COVID-19, the industry's toughness is not strong enough to enlarge the gap. Taking Guangxi as an example, in recent years, the tourism industry of the surrounding provinces such as Yunnan, Guizhou, Hunan, and Jiangxi have maintained a strong growth trend, developed by leaps and bounds, and the scale of the tourism industry has become increasingly strong. Guangxi is obviously in a competitive inferior position. In terms of the tourism industry, as of October 2020, there are 12 national $5 \mathrm{~A}$ tourist attractions in Jiangxi, 9 in Hunan, 8 in Yunnan, 7 in Guizhou, and 7 in Guangxi. As of 2019, there are 3 National Tourist Resorts in Yunnan, 1 in Hunan, 1 in Jiangxi, 1 in Guizhou, 1 in

(1) Data source: Ministry of Culture and Tourism of the People's Republic of China.
Guangxi, 19 five-star restaurants in Hunan, 17 in Yunnan, 15 in Jiangxi, 10 in Guangxi, and 6 in Guizhou. There are many tourist resorts in Guangdong, in terms of cultural industry, as of 2018, there are 12257 cultural market operators in Hunan, 9695 in Yunnan, 6689 in Guizhou, 5877 in Jiangxi, and 5101 in Guangxi. Overall, the scale of cultural industry in Guangxi is less competitive than that in other provinces. ${ }^{\circledR}$ In terms of total tourism revenue, Guangxi's total tourism revenue has always ranked the last among the five provinces from 2015 to 2018, with total tourism revenue of 1024.144 billion RMB in 2019, more than Hunan and Jiangxi, but still lower than Yunnan and Guizhou; in terms of the total number of tourists, Guangxi's total tourism revenue leaped to the second place in 2019 , but there is still a gap with Guizhou. ${ }^{\odot}$ In general, in the competition with the surrounding provinces, Guangxi's cultural tourism industry has no significant advantage, and the industry scale is small, and the growth is relatively slow.

Table2. Comparison of Guangxi cultural tourism industry scale with Yunnan, Guizhou, Hunan, and Jiangxi provinces

\begin{tabular}{|c|c|c|c|c|c|}
\hline Project & Guangxi & Yunnan & Guizhou & Hunan & Jiangxi \\
\hline $\begin{array}{c}\text { National 5A } \\
\text { tourist } \\
\text { attractions }\end{array}$ & $\mathbf{7}$ & 8 & 7 & 9 & 12 \\
\hline $\begin{array}{c}\text { National } \\
\text { Tourist } \\
\text { Resort }\end{array}$ & $\mathbf{1}$ & 3 & 1 & 1 & 1 \\
\hline $\begin{array}{c}\text { Five-star } \\
\text { hotel }\end{array}$ & $\mathbf{1 0}$ & 17 & 6 & 19 & 15 \\
\hline $\begin{array}{c}\text { Cultural } \\
\text { market } \\
\text { management } \\
\text { organization }\end{array}$ & $\mathbf{5 1 0 1}$ & 9695 & 6689 & 12257 & 5877 \\
\hline $\begin{array}{c}\text { Cultural } \\
\text { industry } \\
\text { practitioners }\end{array}$ & $\mathbf{3 . 8 0}$ & 4.49 & 3.85 & 7.16 & 3.02 \\
\hline
\end{tabular}

Data source: Ministry of Culture and Tourism of the People's Republic of China, Statistical Yearbook of Chinese Culture and Tourism (2019).

\subsection{The development orientation is vague and the cultural exploration is not deep}

In recent years, Guangxi's cultural tourism industry has given full play to its unique resource advantages such as landscape, red, ocean, frontier, longevity, and national culture represented by Zhuang's customs. However, there are still some problems such as unclear positioning and vague guidance. General development and lack of specialization lead to the lack of deep cultural exploration and multi-cultural characteristics, which leads to the lack of well-known and core cultural tourism brands, and products such as coastal vacation, ethnic customs, longevity and health care, frontier tour, red blessed land, and other cultural tourism brands are not built enough. The development of high-quality cultural tourism products, characteristic cultural tourism experience products, and routes is insufficient, and the characteristics

(2) Data source: Statistical Yearbook of Chinese Culture and Tourism (2019) 
are not prominent. On the other hand, Sichuan, Guizhou, and other provinces with the rapid development of cultural and tourism industries are developing in multiple directions based on clear and clear development orientation. For example, Sichuan Province aims at "three-nine-giant" (three refers to Sanxingdui, nine refers to Jiuzhaigou, and big refers to giant panda) to create a new business card of Sichuan cultural tourism, Guizhou Province aims at "Mountain Park Province, colorful Guizhou style", and international brand shadow the sound power has increased rapidly. Therefore, Guangxi needs to clarify its development orientation and fully explore its own culture.

\subsection{The development of industrial integration needs to be deepened, and the infrastructure construction needs to be improved}

At present, the deep integration of Guangxi's cultural tourism with agriculture, forestry, health care, sports, and other industries is not enough. There are still some phenomena of simplification and superficializing. The cultivation and development of new forms of cultural tourism, such as cultural tourism performing arts, and night tourism products, need to be strengthened. The supply of cultural tourism products in the region is unbalanced and inadequate. There are still some problems, such as the construction of public cultural tourism service facilities such as tourism distribution center, tourism toilet and village level public cultural service centers, such as the difficulty of land use, the lack of financial investment, and the difficulty of later operation and maintenance. Cultural tourism convenience services, smart tourism, crisis emergency response need to be further strengthened.

\section{Analysis on the development trend of cultural tourism industry of ethnic minority areas in the post-epidemic era}

\subsection{Cultural tourism industry will become a rigid demand industry in the future}

Ethnic minority areas will gradually achieve high-quality economic development, and people's demand for a better life is also rising. The development from high growth to high quality indicates that the cultural tourism industry will become an important industry in the future. After the outbreak of COVID-19, people put forward higher requirements for the high quality of physical, mental, psychological, physiological, social, environmental, moral, and other aspects. With the increase of middleincome groups and the continuous growth of diversified leisure consumption demand, new industries such as nighttime cultural consumption, rural tourism, health care tourism, contactless vacation, suburban tourism, reservation tourism, and online tourism have been activated.

\section{2 "Cultural tourism +" industry deeply integrated development}

The cultural tourism industry can help to protect and develop traditional culture, further explore the characteristic culture of various nationalities and regions, enrich, and improve the intrinsic value of culture and tourism products, promote industrial upgrading, and drive the development of related industries. One of the development paths of the cultural tourism industry is "culture tourism +" integration, that is, through the integration of commercial resources, cultural resources, and tourism resources to form the integration development of Commerce, tourism, and culture, and on this basis, combined with forestry, agriculture, and other industries to form the integration development mode of forestry, commerce, tourism and culture, agriculture, commerce, tourism, and culture. Cultural tourism and its cross-border integration mean an unprecedented integration in the depth and breadth of the industry, which reflects the vertical integration of online and offline science and technology, as well as the horizontal crossdomain cooperation of the industry. The more prominent trend is the deep integration development of the cultural tourism industry and the big health industry, that is, the comprehensive integration development of "sports, medicine, health and tourism", the online and offline integration development, and the big health industry Health culture and tourism is the deep integration and comprehensive development of culture, tourism, health care, medical and other industries. It is the direction of industrial upgrading and has a very broad development space.

\subsection{Pay more attention to economies of scale and demand orientation}

A larger scale or longer value chain arises at the historic moment. The integration of internal and external industrial chains, the further integration of upstream and downstream of industrial chain, and the further concentration of resources form an industrial chain with more complete industrial elements, longer consumption time, and more industry-driven value realization, which extends to all age groups vertically It extends to many fields horizontally. In order to reduce the sunk capital and cost burden, especially the cultural tourism enterprises began to realize the value of the asset light model and began to pay attention to the improvement of the return rate of asset investment, they no longer rely too much on the box office or single income to reduce the sunk capital and reduce the cost burden by improving the cash income and profitability. Market and consumer demand orientation is clearer. New formats, new products, and new services that meet the needs of the modern public and market are more targeted. New tourism formats such as night tourism economy, virtual tourism, research tourism, and health tourism have emerged, and cultural tourism products and services have been continuously updated. 


\subsection{Modernization reform of cultural tourism industry development}

In the future, the development of the cultural tourism industry is closely related to the application of new technologies such as the Internet, 5G, big data, cloud computing, and artificial intelligence, and the industrial development will realize the modernization reform of intellectualization, high-end, digitization, and personalization. ${ }^{[11]}$ Intellectualization is manifested in the application of new technologies such as artificial intelligence and the Internet of things, such as AI intelligent navigation, interactive viewing experience, and virtual scene demonstration; high-end is manifested in paying more attention to improving the quality of products and services, such as exploring and creating high-end boutique tourist attractions and routes, and using digital technology in products and services; digitization is manifested in the construction of industrial digital ecology, the "data monitoring" of smart tourism platform, the digital transformation of cultural tourism industry, release the effect of digitization on the multiplication of cultural tourism industry; personalization, which is reflected in more emphasis on consumer experience, "unmanned service", "virtual reality", "intelligent tour" and so on, have become the basic requirements of the construction of smart tourism for major tourism enterprises and scenic spots.

\section{The key direction of cultural tourism industry development in ethnic minority areas in the post-epidemic era: formats, products, and platforms}

\subsection{Create new formats of the cultural tourism industry}

The development of the cultural tourism industry should fully tap the advantages of the existing industrial development mode, focus on cultivating and developing new formats, strengthen innovative ideas, vigorously develop sightseeing and leisure agriculture, support the development of forest vacation and water conservancy tourism, focus on the development of low altitude tourism, cruise tourism, high-speed rail tourism, sports tourism and other tourism industries, and promote new tourism models such as upstream, suburban tourism and reservation tourism.

\subsubsection{Sightseeing pastime agriculture}

As the integration of primary, secondary, and tertiary industries in rural areas, pastime agriculture and rural tourism are the strategic focus of promoting Rural Revitalization and play an important role in accelerating the revival of the cultural tourism industry. Around the agricultural production activities, relying on the natural environment and resource endowment, fully integrate the rural customs and culture, build a local characteristic leisure agricultural brand relying on agricultural activities, fruit and flower planting, agricultural business activities, develop related industries such as viewing, vacation, shopping, experience, and play, continue to promote agricultural wisdom, agricultural leisure, agricultural tourism industrialization, and create characteristics brand, aim at market demand, release brand effect, build highquality leisure agricultural tourism industry. ${ }^{[12]}$

\subsubsection{Forest vacation and water conservancy tourism}

Forest tourism and water conservancy tourism are emerging areas of the cultural tourism industry. Promote the implementation of forest tourism and water conservancy tourism quality projects, accelerate the construction of industrial development platforms, and deeply integrate tourism resources such as nature reserves, forest parks, and water conservancy projects. Relying on forest resources and National Forest Park, we will build forest family, forest health base, forest eco-tourism, and other advantageous brands, and deeply develop tourism products such as sightseeing, vacation, sports, health preservation, and exploration of the forest system. Relying on the National Water Conservancy Scenic Spot, create a unique water conservancy holiday brand and innovate water conservancy tourism products.

\subsubsection{Multi-type tourism}

It is an inevitable trend for tourism to promote multi-type development. We should encourage cultural and tourism enterprises to innovate tourism products and services, promote the transformation and upgrading of the cultural and tourism industry, focus on the development of cultural tourism, health tourism, low altitude tourism, sports tourism, red tourism, industrial tourism, and other new tourism industries, and promote the development of traditional tourism. Relying on the characteristic resources, digging out the comparative advantages of resources, launching high-quality tourism routes, creating high-quality tourism brands, increasing the promotion of new tourism, strengthening the construction of new tourism guide teams, and comprehensively promoting the development of multi-type tourism.

\subsubsection{New tourism modes, such as online travel, suburban travel, and reservation travel}

With the development of science and technology, the culture and tourism industry will be further highly integrated with new technologies, promoting the development of culture and tourism industry to high-end, intelligent, and humanized. ${ }^{[13]}$ Promote online travel , continuously optimize and upgrade the online supply and demand network platform, accurately match the consumption demand of the cultural tourism market, and open up the key channel for effective communication between cultural tourism enterprises and consumers; promote the near suburb tourism, build the suburban tourism town, and create the suburban tourism boutique line; promote the pre-appointment tourism, strengthen the 
construction of software and hardware supporting facilities, optimize and upgrade the online smart tourism platform, and improve the pertinence, humanization, and refinement of scheduled tours.

\subsection{Cultivate cultural tourism industry characteristic tourism products}

The cultural tourism industry will pay more attention to how to improve people's real feelings and how to consider its products to meet the needs of the market and the public. Therefore, the cultural tourism industry should focus on the demand side and the product side, fully tap the cultural potential, fully meet the needs of the market and consumers, and strive to promote the upgrading of the cultural tourism industry by building high-end brands and international brands.

\subsubsection{Research tourism products}

People's attention to education and love for tourism gives birth to the possibility of "cultural tourism + education" industry linkage. On the micro-level, it constantly adapts to the market demand and develops new research tourism products, such as national defense tourism products, red tourism products, scientific tourism products, industrial tourism products, natural eco-tourism products, historical and cultural tourism products, rural tourism products, modern landscape (city) tourism products. ${ }^{[14]}$ On the macro level, it relies on cultural and natural heritage, characteristic sites, and old revolutionary base areas, patriotic education training bases, etc. will develop the protective display of cultural sites and the integrated experience projects of research, learning, and tourism of site parks, site museums and cultural sites, and build research tourism destinations.

\subsubsection{Medical tourism products}

After the COVID-19, the people paid more attention to their physical health. The demand for cultural tourism products expanded from the initial spiritual satisfaction of the needs to meet the needs of physical and mental health. To meet this demand, cultural tourism and health services were gradually integrated. The data show that the scale of the medical tourism market in 2021 will reach 264.3 billion $\mathrm{RMB}^{\circledR}$. Medical tourism products are the key to market competition. We should take health care as the main body, create a series of medical tourism products such as longevity health care, coastal vacation health care, natural ecological health care, health care resort, theme sanatorium, and cultivate new formats such as medical diagnosis and treatment, medical planting and sightseeing, medical trade exhibition, hot spring health care, forest health care, sports health care.

(1) Data source: China Business Industry Research Institute, Research Report on the Market Development Status and Future Trend of China's Medical Tourism Industry from 2014 to 2018.

\subsubsection{Characteristic ethnic medicine tourism products}

Characteristic ethnic medicine tourism products are the new growth point of the cultural tourism industry in ethnic areas. Ethnic medicine can not only inherit, innovate, highlight the outstanding culture of ethnic minorities, but also meet the needs of the contemporary tourism market, promote the development of national health, and become a booster for "healthy China", and fully pay attention to and tap the value of ethnic medicine such as Zhuang Yao, Develop and promote characteristic ethnic medical tourism products that are combined with traditional Chinese medicine to prevent diseases, enhance physical fitness, and extend life, establish an effective display platform, improve the standard system and management system, and create a collection of medical treatment, medical beauty, rehabilitation, and health care, famous and high-quality products, and ecological health tourism as one of the traditional Chinese medicine national characteristic medical culture health industry brand, forming a characteristic national medical health cultural tourism industry chain, will effectively promote the sustainable development of "ethnic medicine + tourism products".

\subsection{Incubating a high-quality development platform for the cultural and tourism industry}

Gather industrial development efforts, build a highquality development platform for the cultural tourism industry, promote the development of culture and tourism industry cluster based on the platform, encourage cultural and tourism innovation, build a culture and tourism industry cluster area, strengthen the construction of major projects of culture and tourism industry, and continuously promote the development of culture and tourism industry.

\subsubsection{Cultural tourism industry demonstration base}

The cultural tourism industry demonstration base is the key carrier of cultural tourism industry development. Cultural tourism industry demonstration base, demonstration park, and business incubator can provide a key platform for high-quality industrial development, which is more conducive to the introduction and cultivation of enterprises. Further encourage the construction of cultural and creative industrial parks, entrepreneurial incubators, and cultural and creative blocks in various places. ${ }^{[15]}$ Strengthen the guidance of " cultural tourism + innovation and entrepreneurship ", guide the simultaneous development of cultivation and optimization, and take the national cultural industry and tourism industry integration development demonstration zone, national cultural industry park, and national cultural industry demonstration base as the goal to build the cultural and tourism industry demonstration base and 
industrial park suitable for tourism and industry with bright characteristics.

\subsubsection{Cultural tourism creative industry cluster}

The cultural tourism creative industry cluster is of great significance to the accumulation of talents, funds, information, and innovative resources involved in the cultural tourism industry, and is the latest trend in the development of the cultural tourism industry at home and abroad. Introduce and cultivate high-quality cultural tourism creative industries, guide the development of industrial clusters, and strive to build a characteristic cultural tourism town with high brand value, distinctive themes, outstanding characteristics, major demonstration effects, and industrial clustering pulling effects, create a new cultural tourism creative industry cluster area, promote resource sharing among cultural tourism creative enterprises, form economies of scale, technology spillover effects, and promote overall industrial competitiveness.

\subsubsection{Featured arts and crafts industry base}

The improvement of people's living standards will directly expand the demand for the use of arts and crafts. Arts and crafts products in ethnic areas are high valueadded industries with high economic benefits. Building a characteristic arts and crafts industrial base will help to enhance the connotation of cultural tourism industry development and achieve high-quality and high-level development of cultural tourism industry. To explore the establishment of nixing pottery, Zhuang brocade, bronze drum, hydrangea, shell carving, horn carving, wood root carving, and other industrial bases with national and regional characteristics. Enterprises are encouraged to cooperate with arts and crafts parks and master studios to jointly build a new network platform for arts and crafts. Under the guidance of large-scale e-commerce institutions, new marketing models are innovated, online and offline promotion, and personalized marketing are developed, to promote the sustainable development of the arts and crafts industry.

\section{Suggestions on the revitalization of Guangxi cultural tourism industry in the post-epidemic Era}

\subsection{Implement the management mode of positive guidance and negative list}

The management mode that positive guidance and negative list complement each other is the embodiment of the internal development needs of the market economy. On the one hand, we should actively respond to the negative impact of the epidemic, optimize policies such as rent reduction and tax preference for enterprises, introduce various funds to support the construction of cultural tourism infrastructure, promote high-quality cultural tourism products and characteristic service supply projects through government purchase of services, encourage and support social forces to participate in the construction of cultural tourism infrastructure. On the other hand, we should standardize the threshold of cultural tourism market access, further optimize the mechanism of cultural and tourism market access, approval, and supervision, and create a market environment with orderly competition and equal access. ${ }^{[16]}$ Standardize the development of the industry, form a new pattern of government supervision, enterprise autonomy, industry self-discipline, and social supervision, Implement the main responsibilities of the enterprise, improve the comprehensive consideration indicators, credit management, and evaluation and certification systems, strengthen market supervision and establish a safety review supervision and accountability mechanism.

\subsection{Promote the coordinated development of industrial factors}

The revitalization of the cultural tourism industry requires continuous efforts from the three aspects of capital, land, and talents, and the coordinated development of factors to promote the sustainable and healthy development of the cultural tourism industry. First, in terms of capital factors, optimize the industrial credit management system, innovate financial products suitable for the cultural and tourism industry, and broaden the direct financing channels for cultural and tourism projects and enterprises. Second, in terms of land factors, overall land use planning and urban-rural planning should consider the development needs of the cultural tourism industry, bring the land for key industrial projects into the overall land space use planning, and encourage the undeveloped real estate land to be transformed into the land for cultural and tourism projects by adjusting the land use and planning conditions. Third, in terms of talent factors, it is necessary to cultivate the cultural and tourism industry talent team with moderate scale, high professional level, and strong management ability. According to the different purposes, directions, and fields, it is necessary to implement the high-level talent introduction project and focus on strengthening the construction of high-end talent team, to provide strong talent support for the high-quality development of the industry, give full play to the role of colleges and vocational colleges, and build a practical training base, build talent cultivation entity, promote the integration of production and education.

\subsection{Guide and promote project construction}

Projects are the key to development, and the high-quality development of the industry must be supported by highquality project construction. Accelerate the construction of major landmark projects, strengthen tracking services throughout the project, and do a good job of feedback analysis, and solve the problems in time. Actively introduce investment from well-known enterprises at home and abroad, give priority to the introduction of front-line cultural tourism enterprises with scientific research strength and product research center. Combined with the actual situation, optimize, and improve the layout 
of industrial projects, carry out investment promotion activities, plan packaging cultural tourism boutique projects, and build a cultural tourism industry demonstration area with distinctive characteristics, strong industrial strength, perfect service facilities, and outstanding comprehensive effect. Accelerate the cultivation of rural boutique tourism routes, promote the construction of village-level public service centers, tourist toilets, and other public service facilities, accelerate the extension of health cultural tourism to the countryside, and promote the high-quality development of the cultural tourism industry across the region.

\subsection{Deepen the integrated development of the cultural tourism industry}

Use the new development concept to guide the integrated development of the cultural tourism industry, focus on promoting the true integration and deep integration of the industry, and realize the new development advantage of "1+1>2". Make full use of advanced technology to tap, protect, inherit, and develop resources, break resource barriers, and transform resource advantages into new momentum for economic and social development. Aiming at the development trend of individualized and diversified consumption, we will enhance industrial innovation capabilities and core competitiveness, guide new consumption models based on network platforms, and actively cultivate new consumption hotspots such as customized consumption and experiential consumption. Vigorously promote the integration of new technologies such as big data, cloud computing, and artificial intelligence, and accelerate the digital conversion and development and utilization of cultural tourism resources. Promote the in-depth integration of business, travel, and culture, use cultural soft power to enhance tourism competitiveness and commercial attractiveness, fully tap commercial resources, provide commercial services, promote the integrated development of tourism in urban and rural areas, increase tourism supply, and build a new pattern of urban-rural diversified tourism space development.

\subsection{Strengthen international cooperation}

In the context of the dual cycle, the revitalization of the cultural tourism industry should broaden the vision of development. The global epidemic will eventually come to an end, followed by the comprehensive recovery of the cultural tourism industry. To meet the future market, we must focus on strengthening opening and cooperation. Focusing on the " the Belt and Road Initiative" strategy, the new International Land-sea Trade Corridor Strategy, and RCEP, we should do a good job in opening up tourism to the outside world, and strengthen cooperation with other countries in the world, which are represented by ASEAN countries and the " the Belt and Road Initiative ", and innovate in the development of tourism industry dialogue and exchange activities, strengthen the comprehensive connection with advanced regions at home and abroad, vigorously introduce high-quality resources such as talents and funds, consolidate and expand the market scale, and focus on the development of differentiated markets. Promote the construction of overseas Chinese cultural centers and tourism offices based on spreading civilization, exchanging culture, and enhancing friendship, Promote the construction of overseas Chinese cultural centers and tourist offices, unblock the channels for international cultural and tourism industry exchanges, integrate cultural and tourism publicity resources, and build a three-dimensional, allround publicity system.

\section{Conclusion}

This paper holds that the revitalization of the cultural tourism industry is very important for the economic and social development of ethnic minority areas in the future, and the high-quality development of the cultural tourism industry in ethnic minority areas in the post-epidemic era must first achieve industrial revitalization and optimization of business development services. Through the research, it is found that the revitalization of the cultural tourism industry in ethnic minority areas is still facing severe challenges, such as the lack of competitive advantages, the lack of deep exploration of industrial advantages, the vague industrial positioning, and the low degree of integration and development. At the same time, this paper further analyzes and judges the development of the cultural tourism industry in the post-epidemic era, and believes that there are four trends in the future development of the cultural tourism industry: first, the cultural tourism industry has become a rigid demand industry; second, the depth of integration of the culture and tourism industry; third, economies of scale and demand orientation; fourth, modernization. In this trend, ethnic minority areas should combine with their reality, explore the characteristics and advantages to better adapt to future development. Therefore, this paper puts forward three directions for the development of the cultural tourism industry in ethnic minority areas in the future: formats, products, and platforms, and puts forward more detailed development ideas and countermeasures.

In this way, this paper provides a theoretical basis and policy recommendations for the whole process of cultural tourism industry revitalization in ethnic minority areas, which is conducive to the revitalization of the cultural tourism industry in ethnic minority areas in the postepidemic era, to promote high-quality development. However, the key body of cultural tourism industry revitalization is cultural tourism enterprises. How to balance business development? How to make decisions to adapt to the new market demand? How to upgrade products and services and what is the direction of upgrading? These problems are the direction of further research in the future.

\section{Acknowledgment}

LOAN-3501 PRC: Guangxi Regional Cooperation and Integration Promotion Investment Program - Tranche 1 - 
GX-CS7 Project Advisory Support on Strengthening Business Development Service in Guangxi (50050-003)

\section{References}

1. Z. Liu. Integration of Culture and Tourism: Theory, Practice and Future Direction. Frontiers, 2019 (16): 92-97.

2. A. Liu, C. Yang, Q. Ming, H. Zhang, B. Lu. SpatialTemporal Coordination and Driving Forces of Provincial Culture Industry and Tourism Industry in China. ECON GEOGR, 40(06), 203-213(2020).

3. R. Huang, C. Xie, Y. Li. The evolution and effectiveness of China's cultural tourism industry policies from 2009 to2018: An empirical study. Tourism Tribune, 36(01), 27-40(2021).

4. X. Li. Research Progress and Trend of Integration of Chinese Cultural Industry and Tourism Industry: Based on Catespace Analysis. ECON GEOGR, 39(12), 212-220+229(2019).

5. Y. Li. Integrated Development of Culture and Tourism in Ethnic Area of Central \&Western China: Current Situation, Problems and Suggestions. Guizhou Ethnic Studies, 41(07), 121-125(2020).

6. S. Ding, G. Wang, J. Wang, Y. Feng. The Establishment and Analysis of the Index System of County-Level Culture and Tourism Industry in Ethnic Minority Areas. Ethno-National Studies, 2019 (02): 38-51+140.

7. K. Kong, G. Yang. Research on the Integration Path of Rural Culture and Tourism in Ethnic Minority Areas. Social Scientist, 2020 (09): 72-77.

8. A. Deng, Y. Wei, H. Su. China's Cultural tourism industry: The Impact of the Epidemic and Its Overall Revitalization. Social Scientist, 2020 (04): 3-8+161.

9. J. Qian. Culture Tourism Changes in the Postepidemic Era. Tourism Tribune, 35(08), 3-5(2020).

10. W. Fang. The Influence and Adjustment of COVID19 on the Development of Cultural tourism industry in China. Studies on Party and Government, 2020 (04): 24-27.

11. G. Zou, Y. Ma. New Problems, New Opportunities and New Directions of Shanghai's Culture and Tourism Development under the Normal Epidemic Prevention and Control. Tourism Tribune, 36(02), 10-11(2021)

12. S. Geng, S. Zhang. On Rural Tourism and Cultural Industry Coordinated Development under the Background of Rural Revitalization. J N UNIV AGRI (SSE), 21(02), 44-52(2021).

13. L. Tang. The Digitization of Ethic Cultural Consumption in the New Infrastructure for Cultural Tourism. J G UNIV NATION (PSSE), 42(05), 7479(2020).

14. J. Fan, L. Li. Reflections on the Transformation of Historical and Cultural Resources into Cultural Tourism Products. Theory Monthly, 2020(10), 80-88.
15. Y. Wei, B. Dong. Research on the Construction and Impact of Culture Tourism Town Based on Green Development [J]. Frontiers, 2019(23): 122-125.

16. G. Guo. How to Understand and Overall Implement the Negative List System of Market Access. Chinese Public Administration, 2019 (01): 8-11. 